\title{
The Contribution of Small-Airway Abnormalities in Chronic Obstructive Pulmonary Disease Clinical Manifestations: More than a Functional Issue
}

\author{
Marco Contoli ${ }^{\mathrm{a}}$ Nicola Scichilone ${ }^{\mathrm{b}}$ \\ ${ }^{a}$ Research Centre on Asthma and COPD, Department of Medical Sciences, University of Ferrara, Ferrara, and \\ ${ }^{b}$ Department of Biomedicine and Internal and Specialist Medicine (Di.Bi.MIS), University of Palermo, Palermo, Italy
}

The contribution of small-airway abnormalities - i.e., those occurring in the peripheral membranous bronchioles with an internal diameter $<2 \mathrm{~mm}[1,2]$ - in driving the clinical manifestations of chronic obstructive pulmonary disease (COPD) is well recognized and already encapsulated in the definition of the disease [3]. Several studies have already demonstrated the relative contribution of small-airway and lung parenchyma abnormalities to the severity of airflow limitation, mainly related to peripheral airway collapse and/or emphysema $[1,4]$. Furthermore, a milestone study on this topic by Hogg et al. [5] showed strong correlations between the severity of lung function impairment and the degree of luminal occlusion and the inflammatory infiltrate of the small airways in COPD patients. Notably, small-airway abnormalities seem to antedate the development of spirometrically detectable airflow obstruction, as shown in asymptomatic smokers [6]. Taken together, these observations strongly suggest that small-airway inflammatory and structural abnormalities may represent the incipit towards the development and progression of COPD in smokers.

In the latest issue of Respiration, Crisafulli et al. [7] aimed at establishing the prevalence of small-airway impairment in COPD patients, evaluated by the impulse os-

\section{KARGER}

(c) 2016 S. Karger AG, Basel

E-Mail karger@karger.com

www.karger.com/res cillometry system. Interestingly, the prevalence of smallairway impairment was assessed across COPD severity by means of the "A to D grade classification" according to the recent GOLD guidelines [1]. Besides lung function, this classification takes into account the assessment of symptoms/quality of life and the risk of exacerbations as determinants of COPD severity. The authors found a higher impairment in small-airway function in GOLD stages B (symptomatic patients, with mild airflow obstruction) and C (paucisymptomatic patients, but with more severe airflow obstruction) compared to GOLD stage A (paucisymptomatic patients, and mild airflow obstruction); of note, the percentage of patients with smallairway impairment (defined as a peripheral airway resistance [R5-R20] value $>0.07 \mathrm{kPa} \times \mathrm{s} \times \mathrm{L}^{-1}$ at impulse oscillometry system) was significantly lower in GOLD C than in GOLD B. This latter group of patients (individuals who are highly symptomatic despite mild airflow obstruction) has been shown to experience worse long-term survival rates when compared to patients with more severe airflow obstruction but milder symptomatology [8]. Thus, the symptomatic and/or COPD patients with poor quality of life can be those characterized by predominant small-airway abnormalities, which, in turn, contribute to the severity of the clinical manifestation of the disease. 
The current paper has also the merit of having identified a proportion of subjects with an established diagnosis of COPD who do not show functional features of smallairway abnormalities. These findings confirm that the population of COPD patients is heterogeneous not only in terms of symptoms and lung function but also with regard to the prevalent component of the disease (i.e., small-airway disease vs. emphysema). The current findings, together with previous publications $[5,9]$ showing that small-airway abnormalities affect the severity of the clinical manifestation of COPD, call for a more comprehensive lung functional evaluation that should include measurements of the peripheral portion of the airways in a routine manner.

We support the concept that small-airway impairment not only contributes to airflow obstruction in COPD but also, and even more importantly, to the clinical manifestations of the disease hampering the symptom-related quality of life and possibly the long-term prognosis.

\section{References}

1 Contoli M, Bousquet J, Fabbri LM, Magnussen H, Rabe KF, Siafakas NM, et al: The small airways and distal lung compartment in asthma and COPD: a time for reappraisal. Allergy 2010;65:141-151.

2 Scichilone N, Contoli M, Paleari D, Pirina P, Rossi A, Sanguinetti CM, et al: Assessing and accessing the small airways; implications for asthma management. Pulm Pharmacol Ther 2013;26:172-179.

3 Global Initiative for Chronic Obstructive Lung Disease (GOLD): Global strategy for the diagnosis, management, and prevention of COPD (updated 2015). www.goldcopd.com.
4 Burgel PR: The role of small airways in obstructive airway diseases. Eur Respir Rev 2011;20:23-33.

5 Hogg J, Chu F, Utokaparch S, Woods R, Elliott W, Buzatu L, et al: The nature of smallairway obstruction in chronic obstructive pulmonary disease. N Engl J Med 2004;350: 2645-2653.

6 Stănescu D, Sanna A, Veriter C, Robert A: Identification of smokers susceptible to development of chronic airflow limitation: a 13year follow-up. Chest 1998;114:416-425.

7 Crisafulli E, Pisi R, Aiello M, Vigna M, Tzani P, Torres A, Bertorelli G, Chetta A: Prevalence of small-airway dysfunction among COPD patients with different GOLD stages and its role in the impact of disease. Respiration 2017;93:32-41.
8 Lange P, Marott JL, Vestbo J, Olsen KR, Ingebrigtsen TS, Dahl M, et al: Prediction of the clinical course of chronic obstructive pulmonary disease, using the new GOLD classification: a study of the general population. Am J Respir Crit Care Med 2012;186:975-981.

9 Haruna A, Oga T, Muro S, Ohara T, Sato S, Marumo S, et al: Relationship between peripheral airway function and patient-reported outcomes in COPD: a cross-sectional study. BMC Pulm Med 2010;10:10. 